\title{
THERE ARE NO ADVANTAGES BETWEEN LAPAROSCOPIC AND OPEN LIVER RESECTIONS WITHIN AN ENHANCED RECOVERY PROGRAM (ERAS)
}

\author{
Não há vantagens entre as ressecções hepáticas laparoscópicas e abertas dentro de um programa de \\ recuperação avançada (ERAS ou ACERTO) \\ Gustavo Adrian NARI ${ }^{1 \oplus}$, Ernesto Castro GUTIERREZ ${ }^{2}$, Jose Luis LAYUN ${ }^{1 \oplus}$, Laia FALGUERAS ${ }^{2}$, Daniela \\ MARIOT $^{1 \oplus}$, Georgina FERRET ${ }^{2 \oplus}$, Celia CAULA $^{2 \oplus}$, Javier GÓNGORA ${ }^{3 \oplus}$
}

ABSTRACT - Background: The use of a successful Enhanced Recovery After Surgery (ERAS) in colorectal surgery favored its application in other organs, and hepatic resections were not excluded from this tendency. Some authors suggest that the laparoscopic approach is a central element to obtain better results. Aim: To compare the laparoscopic vs. open hepatic resections within an ERAS to evaluate if there are any differences between them. Methods: In a descriptive study 80 hepatic resections that were divided into two groups, regarding to whether they were submitted to laparoscopy or open surgery. Demographic data, those referring to the hepatectomy and the ERAS was analyzed. Results: Forty-seven resections were carried out in open surgery and the rest laparoscopically; in the first group there was only one conversion to open surgery. Of the total, 17 resections were major hepatectomies and in 18 simultaneous resections. There were no differences between procedures regarding hospital stay and number of complications. There was a greater adherence to the ERAS $(p=0.046)$ and a faster ambulation $(p=0.001)$ in the open surgery. Conclusion: The procedure, whether open or laparoscopically done in hepatic resections, does not seem to show differences in an ERAS evaluation.

HEADINGS - Hepatectomy. Laparoscopy. Enhanced recovery after surgery.

RESUMO - Racional: O uso do protocolo Recuperação Otimizada Após Cirurgia (ERAS/ ACERTO) com sucesso na cirurgia colorretal favoreceu a aplicação dele em outros órgãos; as ressecções hepáticas não foram excluídas dessa tendência. Alguns autores sugerem que a abordagem laparoscópica é elemento central para a obtenção de melhores resultados. Objetivo: Comparar as ressecções hepáticas laparoscópicas e abertas dentro de um ACERTO para avaliar se existem diferenças entre as duas técnicas. Métodos: Estudo descritivo comparando 80 ressecções hepáticas divididas em dois grupos, as realizadas por laparoscopia e aquelas por laparotomia. Foram analisados dados demográficos, referentes à hepatectomia e ao ACERTO. Resultados: Foram realizadas 47 ressecções por laparotomia e o restante por laparoscopia; houve apenas uma conversão para laparotomia no grupo da laparoscopia. Do total, 17 ressecções foram hepatectomias maiores e em 18 ressecções simultâneas. Não houve diferenças entre os procedimentos quanto ao tempo de internação e número de complicações. Houve maior adesão ao ACERTO $(p=0,046)$ e deambulação mais rápida $(p=0,001)$ na operação aberta. Conclusão: O procedimento, seja laparotômico ou laparoscópico nas ressecções hepáticas, não parece mostrar diferenças em uma avaliação ERAS/ACERTO.

DESCRITORES: Hepatectomia. Laparoscopia. Recuperação pós-cirúrgica melhorada.

\section{Central message}

ERAS programs are safety and feasible for liver resections. No differences were observed between the open and laparoscopic approach.

Perspective
This paper demonstrates that open or laparoscopic
hepatectomies do not present differences when
performed within an ERAS program, supporting
open performance in centers with experience in
liver surgery that do not have the technology for the
minimally invasive approach.

\section{Perspective}

hepatectomies d performed within an ERAS program, supporting liver surgery that do not have the technology for the minimally invasive approach.

\section{Correspondence:}

Gustavo Adrian Nari

E-mail: gusnari@hotmail.com
Financial source: none

Conflict of interest: none

Received for publication: 26/11/2020

Accepted for publication: $23 / 02 / 2021$ 


\section{INTRODUCTION}

$\mathrm{T}$ he Enhanced Recovery After Surgery (ERAS) programs were introduced by Kehlet and Wilmore ${ }^{10}$ in colorectal surgery, later being used in different diseases and viscera ${ }^{4}$.

The majority of authors agree that the decrease of hospital stay, costs and complications are the main advantages $s^{8,11,13,20,23,24,25}$. Hepatectomies haven't been excluded from this trend and multiple studies, sometimes with heterogeneous programs, have been published reporting encouraging results, noticing an important decrease in hospital stay and with that a lowering of costs of US $\$ 2,000^{3,12}$ or even more ${ }^{25}$. Another point that some authors mention is a decrease in the number of complications, although the literature is quite contradictory in this issue ${ }^{5}$. In a study previously published where we compare open hepatectomies due to metastasis of colorectal origin inside and out of an ERP, we observed that there was a reduction of up to $50 \%$ in hospital stay but no difference in the percentage of complications ${ }^{14}$.

The minimally invasive approach is considered by some authors fundamental for the success of an ERAS ${ }^{3}$. Papers comparing open vs. laparoscopic liver resections within an ERAS are scarce.

The aim of this study was to compare the results between open vs. laparoscopic hepatectomies within an identical ERAS by two surgical teams.

\section{METHOD}

\section{Study design}

This is a cross-sectional, observational and descriptive analysis of patients treated by two surgical teams in three different institutions on the application of an ERAS comparing the results of open vs. laparoscopic hepatectomies in three years. The laparoscopic hepatectomies were carried out in their totality by the surgical team of Hospital Josep Trueta, Girona, Espanha, while the majority of the open hepatectomies were carried out in the other two institutions.

Enhanced Recovery After Surgery (ERAS) program

An ERAS with basic points with a higher level of evidence recommended by the ERAS society was agreed by both teams and applied to all patients in the study with previously signed informed consent.

\section{Preoperative}

Complete information about the procedure, advantages and full scope of it, actively involving the patient in their development.

\section{Preoperative day}

Diet night before the surgery: fluid intake of liquids high in carbohydrates up to $2 \mathrm{~h}$ prior surgery; use of low molecular weight heparin $12 \mathrm{~h}$ before surgery.

\section{Intraoperative}

Fluid therapy control (near zero balance); restriction where possible use of drains by choice of each surgeon; nasogastric intubation with withdrawn at the end of surgery; epidural catheter or intrathecal morphine.

\section{Postoperative}

Withdrawal of fluid therapy within the first $48 \mathrm{~h}$; regulated use of prokinetics; start oral liquid intake within the first $24 \mathrm{~h}$; start of a regular diet within $48 \mathrm{~h}$; bladder catheter removal within the first $24 \mathrm{~h}$; early beginning of ambulation.
Criteria to consider total functional recovery

Pain control with oral analgesics; no use of intravenous fluids; mobilization by their own means at the preoperative level or similar; solid food intake; normal bilirubin levels or starting to decrease towards normality; total functional recovery assessed at the time of patient discharge.

The adherence to the ERAS was made through a checklist with the points of the program previously described in which each surgeon marked "yes" or "no" according to compliance with each of the items on the list.

Demographic data was evaluated, as were those referring to etiology and hepatectomies, the postoperative course and from the data from the ERAS. The hepatectomies were classified according to the Brisbane classification; the bile leakage according to the proposal of the International Study Group of Liver Surgery; liver failure according to the 50/50\%; criterion and complications according to the Dindo-Clavien classification.

Surgery with controlled decrease in central venous pressure was performed in all patients and mean arterial pressure was measured in all of them. Lower limb bandage was used in all patients as a measure of anti-thrombotic prophylaxis. Antibiotic prophylaxis was used in all patients. Intraoperative ultrasound was used in all patients to investigate lesions and to recognize intra-hepatic anatomy.

\section{Statistical analysis}

Categorical variables were described using proportions, symmetric continuous variables using mean and standard deviation, and asymmetric continuous variables using median and range. The chi-square test was used to compare proportions between groups as well as Fisher's exact test when appropriate. For the comparisons of average between groups, the Mann-Whitney U test was used, which was considered more appropriate than Student's T test due to the reduced sample size. In all cases, a bilateral alpha error of $<5 \%$ was considered. The data was analyzed with the PASW 18 software.

\section{RESULTS}

Eighty liver resections were incorporated into the study, 47 resections $(58.7 \%)$ with the open approach and the rest laparoscopically; there was only one conversion (3.03\%). Of the total, 17 (21.2\%) were major hepatectomies (resection of three or more consecutive Couinaud liver segments) and in $18(22.5 \%)$ simultaneous resections of liver metastases and primary colorectal cancer were performed. $85 \%$ of the resections were indicated because of malignant disease and of these the vast majority by metastases from colorectal cancer. The hospital stay of the entire series had an average of 3.9 days, adherence to the protocol was of $72.5 \%$ and full recovery of $85 \%$. The rest of the general data of the series can be seen in Table 1.

Table 2 shows the demographic data of both groups where no differences were observed regarding age, gender or BMI, highlighting a greater number of patients with lower surgical risk in patients undergoing open surgery and a higher alcohol consumption in the group of patients who underwent laparoscopic surgery.

Table 3 shows the data regarding hepatectomies. Although there was no statistical significance, in the open surgery group there were a greater number of major liver resections (12-25.5\% vs. $4-15.1 \%$ ) and simultaneous resections of both the liver metastases and the primary colorectal tumor $(14-29.7 \%$ vs. $1-12.1 \%)$. 
TABLE 1 - General data of the series in 80 liver resections

\begin{tabular}{|c|c|}
\hline Variable & Number \% Median rank \\
\hline Age & 59.28 years $(28-84)$ \\
\hline Male & 47 (53.75\%) \\
\hline BMI & $26.76(18-46)$ \\
\hline Major hepatectomies & $17(21.25 \%)$ \\
\hline Open way & 47 (58.75\%) \\
\hline Simultaneous resection & $18(22.5 \%)$ \\
\hline Repeated resection & 10 (12.5\%) \\
\hline Operative time in minutes & $204 \min (20-530)$ \\
\hline Hospital stay & 3.9 days $(2-9)$ \\
\hline Hospital re-entry & $4(5 \%)$ \\
\hline Re-operation & $1(1.25 \%)$ \\
\hline Adherence & $58(72.5 \%)$ \\
\hline Full recovery & 68 (85\%) \\
\hline Indication & 80 \\
\hline MTS CCR & 48 \\
\hline $\mathrm{HCC}$ & 8 \\
\hline MTS breast & 4 \\
\hline Other MTS & 8 \\
\hline Hydatidosis & 5 \\
\hline Hemangioma & 3 \\
\hline FNH & 2 \\
\hline Others & 2 \\
\hline Complications & $13(16.25 \%)$ \\
\hline
\end{tabular}

TABLE 2 - Demographic data

\begin{tabular}{|l|ccc}
\multicolumn{1}{c}{ Variable } & $\begin{array}{c}\text { Open surgery } \\
(\mathbf{n}=47)\end{array}$ & $\begin{array}{c}\text { Laparoscopic } \\
\text { surgery }(\mathbf{n}=33)\end{array}$ & $\mathrm{p}$ \\
\hline Male & $51.06 \%$ & $57.57 \%$ & 0.565 \\
\hline $\begin{array}{l}\text { Median age -SD } \\
\text { (years) }\end{array}$ & $57+/-14$ & $61+/-17.5$ & 0.090 \\
\hline ASA2 & $44.68 \%$ & $15.15 \%$ & 0.013 \\
\hline ASA3 & $55.31 \%$ & $81.81 \%$ & \\
\hline ASA4 & - & $3.03 \%$ & \\
\hline Alcohol comsumption & $4.25 \%$ & $21.21 \%$ & 0,018 \\
\hline Tabaco & $19.14 \%$ & $30.30 \%$ & 0,248 \\
\hline BMI $\left(\mathrm{kg} / \mathrm{m}^{2}\right)$ & 26.24 & 27.27 & 0.742 \\
\hline Physical excercise & $29.78 \%$ & $51.51 \%$ & 0.050 \\
\hline
\end{tabular}

TABLE 3 - Data of liver resections

\begin{tabular}{|c|c|c|c|}
\hline Variable & $\begin{array}{l}\text { Open surgery } \\
(n=47)\end{array}$ & $\begin{array}{c}\text { Laparoscopic } \\
\text { surgery }(n=35)\end{array}$ & $p$ \\
\hline Major hepatectomy & $25.53 \%(12)$ & $15.15 \%(5)$ & 0.354 \\
\hline Simultaneous resection & $29.78 \%(14)$ & $12.12 \%(4)$ & 0.062 \\
\hline Operative time (min) & 155 & 232.62 & 0.001 \\
\hline Blood loss $>300 \mathrm{ml}$ & $46.80 \%$ & $57.57 \%$ & 0.393 \\
\hline $\begin{array}{l}\text { Complications } \\
\text { Dindo Clavien }\end{array}$ & $\begin{array}{c}14.89 \%(7) \\
I / 5 \\
I I / 1 \\
V / 1\end{array}$ & $\begin{array}{c}18.18 \%(6) \\
I / 1 \\
I I / 3 \\
\text { IIIA/2 }\end{array}$ & 0.695 \\
\hline Use of drains & $46.8 \%(22)$ & $21.21 \%(7)$ & 0.019 \\
\hline $\begin{array}{l}\text { Hospital stay without } \\
\text { re-entry (days) }\end{array}$ & 4 & 3 & 0.5323 \\
\hline $\begin{array}{l}\text { Hospital stay with re- } \\
\text { entry (days) }\end{array}$ & 5.25 & 7 & 0.235 \\
\hline
\end{tabular}

In both groups there were no differences in terms of complications ( $n=7,14.8 \%$ vs. $n=6,18.1 \%$ ), in the open surgery group there were five complications type I and one complication type 5 that represents the only cause of death of the series, while in the laparoscopic approach there were more complications type II and III. The hospital stay did not present significant differences between both groups, both with and without readmission, the average number of days in the laparoscopic surgery group when readmissions were counted amounted to seven days, and this was partly due to the fact that complications in this group were more serious. There was a significant difference $(p=0.019)$ regarding the placement of drains in the abdominal cavity; they were used 22 times (46.8\%) in open surgery and seven (21.2\%) in laparoscopic surgery. The greater number of simultaneous and major resections in open surgery group conditioned this difference. On the other hand, the operative time was shorter in open surgery than when the laparoscopic approach was performed $(p=0.001)$

There was a single death due to respiratory failure in the immediate postoperative period after a right trisectionomy (2.12\%), while in the laparoscopic approach there was no mortality.

TABLE 4 - ERAS results

\begin{tabular}{|l|c|c|c|}
\multicolumn{1}{c}{ Variable } & $\begin{array}{c}\text { Open surgery } \\
(\mathbf{n}=47)\end{array}$ & $\begin{array}{c}\text { Laparoscopic } \\
\text { surgery }(\mathbf{n}=33)\end{array}$ & $\mathrm{p}$ \\
\hline $\begin{array}{l}\text { Adherence } \\
\text { Start of ambulation }\end{array}$ & $\begin{array}{c}16.85 \% \\
(\mathrm{Rl}: 12-24)\end{array}$ & $\begin{array}{c}60.60 \% \\
\text { (Rl:23-36) }\end{array}$ & 0.046 \\
\hline $\begin{array}{l}\text { Bladder catheter removal } \\
\text { (hours) }\end{array}$ & 18 & 24 & 0.001 \\
\hline $\begin{array}{l}\text { Amdominal drains } \\
\text { removal (hours) }\end{array}$ & 38.04 & 80 & 0.122 \\
\hline $\begin{array}{l}\text { Intravenous fluis removal } \\
\text { (hours) }\end{array}$ & 36 & 30 & 0.255 \\
\hline $\begin{array}{l}\text { Full recovery } \\
\text { Hospital re-entry }\end{array}$ & $\begin{array}{c}80.85 \%(38) \\
2(2.5 \%)\end{array}$ & $\begin{array}{c}90.90 \%(30) \\
2(2.5 \%)\end{array}$ & 0.215 \\
\hline
\end{tabular}

Table 4 shows the results of ERAS implemented, where the outstanding data and the most significant difference observable are due to a greater adherence to the program $(p=0,046)$, the start of ambulation $(p=0.001)$ and the withdrawal of the bladder catheter $(p=0.022)$ that point in favor of open surgery. Meanwhile, although there was no significant difference in terms of full recovery, better performance was observed in the laparoscopic surgery group.

\section{DISCUSSION}

The success of the application of an ERAS in major colon and rectal surgery has encouraged its application in other organs. The use of an ERAS in liver surgery has been increasingly indicated in different surgery services. It is known that the application of an ERAS has been beneficial due to the decrease in hospital stay and therefore costs ${ }^{17,22}$. Only few studies compared the results of these programs in open vs. laparoscopic hepatectomies. The minimally invasive approach has been considered to be one of the main points in regards to obtaining a faster and better quality of functional recovery when compared to the open approach in patients undergoing liver resections $16,18,19$. These studies indicate a great improvement in terms of hospital stay, decrease in complications and less blood loss with the consequent decrease in transfusion needs when compared to liver resections with an open approach, with the addition that the laparoscopic approach would decrease the postoperative ileus time. Other authors assure that the laparoscopic approach favors an earlier start of oral intake and a lesser need for intravenous analgesics; all these studies were performed outside an ERAS $16,18,19$ and our study mainly aimed to compare both approaches within one.

For this study, an ERAS was agreed between two surgical teams, taking into account the points with the highest level of evidence recommended and suggested by the ERAS Society.

From the analysis of the results and attending to the primary objectives of our work, we noted that the hospital stay did not show significant differences between the two groups. Most series report a hospital stay of between 3-7 days ${ }^{47,53}$ confirming a decrease of up to $50 \%$ in hospital days when compared to conventional management outside an ERAS.

The decrease in hospital stay produces a significant reduction in costs ${ }^{24,46}$. However, there were patients who underwent different simultaneous resections which could have prolonged the hospital stay. This did not happen when we consider the results reported in other studies ${ }^{26,30}$. 
When we compare the complications between the open and laparoscopic approach, there were no differences either, this percentage of complications is similar to a previous publication ${ }^{15}$. In the open surgery group, there were a greater number of Dindo-Clavien type I complications and they were more related to complications of the surgical wound and a serious complication that triggered the only death in the series. On the laparoscopic approach, there were a greater number of type II and III complications, which favored a greater number of days in stay during the readmissions in this group. At this point, one might wonder if a greater use of drains in laparoscopic surgery would not have significantly reduced the number of complications and therefore hospital stay. The percentage of complications reported in other series is around $30 \%{ }^{26}$, a probable explanation for a low number of complications in our groups would be a high number of minor liver resections, this would also coincide with some authors who noted different results when stay and morbidity were compared between minor and major hepatectomies; on the other hand, some authors report a percentage similar to our in laparoscopic resections, although the number of minor hepatectomies in these series was predominant, reaching $91 \%$ in Savikko's series 22

Adherence to the ERAS showed a difference in favor of open surgery $(p=0.046)$, in the same way as the start of ambulation $(p=0.001)$. A possible explanation for this difference in the start of ambulation may lie in two points: on the one hand, that laparoscopic surgery requires the use of pneumoperitoneum, which may favor the appearance of omalgia and other disorders that would delay the start of mobilization; and on the other, that when the surgical times were compared, there were differences in favor of the open technique $(p=0.001)$, it is known that longer anesthetic and surgical times have an impact on recovery time and therefore on the start of ambulation and the decrease in complexity of the patients. Some authors report very detailed information on what is expected of patients in the postoperative period, a multidisciplinary approach and a staggered start of the mobilization of the patient indicating that they remain seated in bed or in a chair in the first $24 \mathrm{~h}$ to later progress to ambulation favors a greater adherence ${ }^{27}$. At this point we fully agree that information to the patient and the family is essential to receiving collaboration in order to achieve greater adherence.

Blood loss is also a factor that can affect postoperative adherence, playing an important role in the decrease of the complexity in patients, different authors have stated that the laparoscopic approach has a lower rate of bleeding when compared with open approaches in the comparison of both groups there were no differences regarding blood loss ${ }^{30}$.

Full recovery at discharge did not show significant differences either $(p=0.215)$ although in laparoscopic surgery there was a higher percentage of patients who reached this state. We noted in open surgery that postoperative pain control at discharge was less satisfactory. It is likely that, as well as the use of pneumoperitoneum and a longer operative time could negatively affect the start of ambulation, minimal invasive procedures achieve better control of postoperative pain at discharge favoring greater total recovery. Another point that we analyzed and that although it did not present a significant difference but could play an important role in pain control is that in the open surgery group there were a greater number of simultaneous resections. Wong Lun Hing et $\mathrm{al}^{28}$ achieved full recovery in the majority of their patients on the $5^{\text {th }}$ day of the postoperative period, which coincides with our results.

Other data that was compared was the use of cavity drains, which was greater in open surgery, an explanation for this difference lies in a greater number of simultaneous resections. In the open surgery group, drainage was placed in $46.8 \%$, some series report the use of drains in around $20 \%$ with the open technique ${ }^{3}$. We agree with the authors who report that the use of drains is unnecessary in a significant number of patients ${ }^{29}$; for this purpose, it would be correct to protocolize in which patients they should be placed. Some authors suggest that the placement of drains in hepatectomies should be performed in patients whose surgery lasts more than $350 \mathrm{~min}$, a blood loss of more than $650 \mathrm{ml}$ or with bile leak or doubt regarding it during surgery.

We can express that our study presents several weaknesses: there was no randomized distribution of patients, the number of patients should be greater, and laparoscopically operated patients have been operated by a single center. On the other hand, an ERAS in liver surgery brings benefits to patients in terms of hospital stay in coincidence with other authors. Perhaps a greater number of cases, the division between major and minor hepatectomies and the exclusion of simultaneous resections would allow us to produce more certain result.

\section{CONCLUSION}

The procedure, whether open or laparoscopically, done in hepatic resections, does not seem to show differences in an ERAS evaluation.

\section{ACKNOWLEDGEMENTS}

\author{
To Miss Lucia Barquin for the translation of the text
}

\section{REFERENCES}

1. Bai X, Zhang X, Lu F, Li G, Gao S, Lou J, Zhang Y, Ma t, Wang J, Chen W, Huang $B$. . "The implementation of an enhanced recovery after surgery (ERAS)program following pancreatic surgery in an academic medical center of China". Pancreatology 2016, 16:665-70

2. Bekki Y, Yamashita $Y$, Itoh $S$, Harimoto N, Shirabe $K$, Maehara $Y$ "Predictors of efectiveness of prophylactic drain after hepatic resection". World J Surg 2015, 39:2543-2549.

3. Connor S, Cross A, Sakowska M, Linscott D, Woods J. "Effects of introducing an enhanced recovery after surgery programme for patients undergoing open hepatic resection". HPB 2013, 15:294-301.

4. Dai J, Jiang Y, Fu D. "Reducing postoperative complications and improving clinical outcome:Enhanced recovery after surgery in pancreatticoduodenectomy. A retrospective cohort study". Int J Surg 2017, 39:176-81

5. DasariB,RahmanR, ShakeebK, BennettD,HodsonJ, IsaacJ,Marudanayagan J, Mirza D, Muiesan P, Roberts K, Sutcliffe R. "Safety and feasibility of an enhanced recovery pathway after a liver resection: prospective cohort study." HPB 2015, 17:700-706

6. Halls M, Berardi G, Cipriani F, Barkhatov L, Lainas P, Harris S et al. "Development and validation of a difficulty score to predict intraoperative complications during laparoscopic liver resection." Br J Surg 2018, 105:1182-91.

7. Hasegawa Y, Wakabayasi G, Nitta H, Takahara T, Katagiri H, Umemura A et al. "A novel model for prediction of pure laparoscopic liver resection surgical difficulty". Surg Endosc 2017, 31:5356-63.

8. Jones C, Kelliher L, Dickinson M, Riga A, Worthinton T, Scott M, Vandrevala T, Fry C, Karanjia N, Quiney N. "Randomized clinical trial on enhanced recovery versus standard care following open liver resection". Br J Surg 2013, 100:1015-24.

9. - Kawuaguchi Y, Fuks D, Kokudo N, Gayet B. "Difficulty of laparoscopic liver resection: proposal for a new classification." Ann Surg 2018, 267:13-17.

10. Kehlet $\mathrm{H}$, Wilmore D. "Multimodal strategies to improve surgical outcome". Am J Surg 2002, 183:630-41.

11. Le $L$, Jinming $C$, Zhonghua L, Qiang L, Ying S. "Enhanced recovery program versus traditional care after hepatectomy": Medicine 2017, 96: 38-44.

12. Liang $X$, Ying $H$, Wang $H, X u H, Y u H$, Cai L, Wang $Y$, Tong $Y$, Ji L, Luo $R$, Cai $X$. "Enhanced recovery program versus traditional care in laparoscopic hepatectomy". Medicine 2016, 95 (8): e2835. DOI 10.1097/MD.0000000000002835.

13. Muller S, Zalunardo M, Hubner M, Clavien P, Demartines $N$, Zurich fast track Study Group. "A fast track program reduces complications and lenght of hospital stay after open colonic surgery". Gastroenterology 2009, 136:942-47. 
14. Nari G, Molina L, Gil F, Viotto L, Layun J, Mariot D et al. Enhanced recovery after surgery (ERAS) in open liver resections of hepatic colorectal metastasis. Initial experience. Rev Argent Cirug 2016, 108:9-13

15. Nari G, Castro-Gutierrez E, Layún J, Falgueras-Verdaguer L, Mariot D, Albiol-Quer $\mathrm{M}$ et al. "Open versus Laparoscopic hepatectomies within an ERAS (Enhanced Recovery after Surgery) program. Are there differences?" Cir Ciruj 2020, 88:49-55

16. Nguyen K, Marsh J, Tsung A, Steel M, Gamblin T, GellerD. "Comparative benefits oflaparoscopic vs open hepatic resection: a critical appraisal". Arch Surg 2011, 146:348-56

17. Page A, Ejaz A, Spolverato G, Zavadsky T, Grant M, Galante D, Wick E, Weiss M, MaKary M, Wu C, Pawilk T. "Enhanced recovery after surgery protocols foropen hepatectomy physiology, immunomodulation and implementation." J Gastrointest Surg 2015, 19:387-99.

18. Parks K, Kuo Y, Davis J, O’Brien B, Hagopian E. "Laparoscopic versus open liver resection :meta-analysis of long term outcome". HPB 2014, 16:109-18

19. Rao A, Ahmed I. "Laparoscopic versus open liver resection for benign and malignant hepatic lesions in adult". Cochrane database Syst Rev (5):CD1016. Doi.10.1002/14651858.CD010162.pub2.

20. Roulin D, Donadini A, Gander S, Griesser A, Blanc C, Hubner M, Schafer M, Demartines N. "Cost-effectiveness of the implementation of an enhanced recovery protocol for colorectal surgery" Br J Surg 2014, 100:1108-14.

21. Russolillo N, Maina C, Fleres F, Langella S, Lo Tesoriere R, Farrero A. "Comparison and validation of three difficulty scores systems in laparoscopic liver surgery: a retrospectiv analysis on 300 cases." Surg Endosc 2020, doi.org/10.1007/s00464-019-07345-1.

22. Savikko J, Vikatmaa L, Hiltunen AM, Mallat N, Tukiainen E. "Enhanced recovery in laparoscopic liver surgery". Surgical Endoscopy 2020 https://doi.org/10.1007/s00464-020-07470-2
23. Teixeira UF, Fontes PRO, Conceição CWN, Farias CAT, Fernandes D, Ewald IP, Vitola L, Mendes FF. Implementation of enhanced recovery after colorectal surgery (ERAS) protocol: initial results of the first brazilian experience. Arq Bras Cir Dig. 2019 Feb 7;32(1):e1419. doi: 10.1590/0102-672020180001e1419. PMID: 30758467; PMCID: PMC6368157.

24. Teixeira UF, Goldoni MB, Waechter FL, Sampaio JA, Mendes FF, Fontes PRO. Enhanced recovery (ERAS) after liver surgery:comparative study in a brazilian terciary center. Arq Bras Cir Dig. 2019 Feb 7;32(1):e1424. doi: 10.1590/0102-672020180001e1424. PMID: 30758472; PMCID: PMC6368150.

25. Thornblade L, Seo Y, Kwan T, Cardoso J, Pan E, Dembo G et al. "Enhanced recovery via peripheral nerve block for open hepatectomy". J Gastrointest Surg 2018, 22;981-88.

26. Van Dam R, Hendry P, Coolsen M, Bemelmans M, Lassen K, Revhaug A Fearon KC, Garden OJ, Dejong CH; Enhanced Recovery After Surgery (ERAS) Group. "Initial experience with a multimodal enhanced recovery after surgery programme in patients undergoing liver resection". $\mathrm{Br}$ J Surg 2008, 95:969-75.

27. Wong-Lun-Hing E, van Dam R, van Breukelen G, Tanis $P$, Ratti F, van Hillegersberg R, Slooter GD9, de Wilt JH10, Liem MS11, de Boer MT12, Klaase JM13, Neumann UP1,3, Aldrighetti LA7, Dejong CH1,2,14,3; ORANGE II Collaborative Group. "Randomized clinical trial of open vs laparoscopic left lateral hepatic sectionectomy within an enhanced recovery after surgery programme". Br J Surg 2017, 104:525-35.

28. Wong Lun Hing E, van Dam R, Heijnen L, Busch O, Terkivatan T, van Hilleegersberg $\mathrm{R}$ et al "Is current perioperative practice in hepatic surgery based on enhanced recovery after surgery (ERAS) principles?". World J Surg 2014, 38:1127-1140.

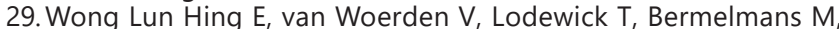
Olde Damink S, Dejong C, Van Dam R. "Abandoning prophylactic abdominal drainage after hepatic surgery: a 10 years of non-drain policy in an enhanced recovery after surgery environment". Dig Surg 2017, doi:10.1159/000455246. 